\title{
Determinants of health facility utilization during childbirth among 15 to 49-year-old women in Uganda: evidence from the Uganda demographic health survey 2016
}

\section{Quraish Sserwanja}

Programmes Department, GOAL, Khartoum

David Mukunya

Department of Public Health, Busitema University

Milton Musaba

Department of Obstetrics and Gynaecology, Busitema University, Tororo Joseph Kawuki

Center for Health Behaviours Research, JC School of Public Health and Primary Care, The Chinese University of Hong Kong

Freddy Eric Kitutu ( $\square$ kitutufred@gmail.com )

Makerere University College of Health Sciences https://orcid.org/0000-0003-2277-9572

Research article

Keywords: Health facility, Childbirth, Utilization, Women and Uganda

Posted Date: December 1st, 2020

DOI: https://doi.org/10.21203/rs.3.rs-113832/v1

License: (c) (i) This work is licensed under a Creative Commons Attribution 4.0 International License.

Read Full License 


\section{Abstract}

\section{Background}

Almost all maternal deaths and other related morbidities occur in low income countries. Childbirth supervised by a skilled provider in a health facility is a key intervention to prevent maternal and perinatal morbidity and mortality. Our study aimed to establish the determinants of health facility utilization during childbirth in Uganda.

\section{Methods}

We used Uganda Demographic and Health Survey (UDHS) 2016 data of 10,152 women aged 15 to 49 years. Multistage stratified sampling was used to select study participants and we conducted multivariable logistic regression to establish the determinants of health facility utilization during childbirth. All our analyses were done using SPSS version 25.

\section{Results}

The proportion of women who gave birth from a health facility was $76.6 \%(7,780 / 10,152:$ ( $95 \%$ Cl: 75.8 77.5). Odds of health facility birth decreased with older age. Women aged 15-19 years were twice as likely to give birth from health facilities compared to women aged 40 to 49 years (AOR=2.25; $95 \% \mathrm{Cl}$ : 1.71 2.96). Women residing in urban areas were more likely to give birth from a health facility compared to those in rural areas (AOR=1.48; $95 \% \mathrm{Cl}$ : 1.18- 1.86), as well as those who attended ANC (AOR=3.60; $95 \%$ Cl: 2.47- 5.24).

Women in the Northern region were more likely to use health facilities compared to those in the Central region ( $A O R=2.42 ; 95 \% \mathrm{Cl}: 1.81-3.22$ ). Odds of health facility birth increased with rise in wealth index and education level. Women with higher education ( $A O R=5.15 ; 95 \% \mathrm{Cl}: 2.79-9.52)$ and those in the richest wealth index (AOR=5.14; 95\% Cl: 3.72- 7.10) were five times more likely to give birth from a health facility compared to those with no education and those in the poorest wealth index respectively.

\section{Conclusion}

Health facility utilization during childbirth was high and positively associated with; decreasing age, increasing level of education and wealth index, urban residence, Northern region and ANC attendance. We recommended that interventions to promote health facility childbirths in Uganda should target the poor, less educated and older women especially those residing in rural areas.

\section{Background}

Approximately 830 women die daily globally from pregnancy related causes [1]. More than half of these deaths occur in sub-Saharan Africa [2]. Majority of these deaths are due to direct obstetric complications $[2,3]$ that can be prevented through early detection and intervention by a skilled healthcare provider $[1,4]$. 
Sadly, a significant proportion of women in low and middle income countries still give birth at home unattended by skilled health workers [5].

Over the last two decades, Uganda has achieved a steady reduction in the maternal mortality ratio currently standing at 336 deaths per 100,000 live births with substantial variation across Ugandan regions [6]. However, the current maternal mortality ratio deaths is still high in comparison to the SDG target of 70 deaths per 100,000 live births by 2030 [7].

Recent evidence on the determinants of health facility childbirths in Uganda utilizing a nationally representative sample is lacking. Ugandan studies on determinants of health facility childbirths have focused on sub national scope such as districts or regions while some are not recent [8-11]. Mbonye et al. focuses on institutional predictors of health facility delivery using data from 2010 national health facility survey [12]. Rutaremwa et al. reports factors associated with a composite outcome - desirable maternal health care package which combines ANC, skilled birth attendance, post-natal care and health facility utilization during childbirth from the 2011 Uganda Demographic and Health Survey (UDHS) hence making it hard to identify the predictors of health facility childbirth alone [13]. Another study by Micah et al. analyses the 2009-2011 Uganda National Panel Survey data and reports community factors, albeit from a smaller sample size of 3310 [1]. An understanding of the determinants of health facility childbirths in Uganda is crucial to identifying key priority areas that are necessary in developing interventions that promote safe childbirths. Our study aimed to establish the determinants of health facility childbirths in Uganda.

\section{Methods}

\section{Data Source}

We used secondary data of the 2016 nationally representative UDHS collected from June to December 2016 [6]. The survey was implemented by the Uganda Bureau of Statistics (UBOS) with the technical assistance of Inner City Fund (ICF) International through the USAID-supported MEASURE DHS project [6]. The survey inquired about household members' and individual characteristics using household questionnaire, women's questionnaire, men's questionnaire and biomarker questionnaire [6]. The data used in this study were collected using the women's questionnaire. Women were asked about the place of delivery for their most recent live birth in the 5 years preceding the survey [6].

\section{Study setting}

Uganda has a tiered six level health system from the highest level of national referral hospitals to the lowest at the community $[14,15]$. It is a mixed health system where public and private health providers co-exist [15]. Over 25 years ago, Uganda adopted a decentralized approach to service delivery with local government at districts overseeing, managing and mobilizing resources for service delivery including healthcare services [15]. The Ugandan government abolished user fees in 2001 in all public health 
facilities. However, the health system still faces inadequate staffing, low pay, shortage of medicines and poor infrastructure that have negatively affected health service provision and utilisation [15].

\section{Study sampling and participants}

DHS employed two stage cluster sampling technique where the census enumeration areas were the primary sampling units while households comprised the second stage of sampling [6]. The enumeration areas were selected from the 2014 population and housing census sample frame [6]. Women aged 15 to 49 years who were either permanent residents or slept in the selected household the night preceding the survey were eligible for inclusion in the Uganda's demographic health survey 2016 [6]. Of the 18,506 women who consented and filled in the questionnaires, 10,152 responded to the question asking about place of delivery considering their most recent live birth in the five years preceding the survey [6].

\section{Variables}

\section{Dependent variables}

Birth outside health facility was referred to as home delivery and was coded as zero (0) while health facility delivery was coded as one (1).

\section{Independent variables}

This study included determinants of health facility childbirths basing on evidence from available literature and data $[2,5,16,17]$. Ten explanatory variables were used: (1) maternal age, (2) wealth index, (3) level of education, (4) place of residence, (5) region, (6) marital status, (7) working status, (8) ANC attendance, (9) sex of household head and (10) household size. Maternal age was categorized as; (15-19 years, 20-29 years, 30-39years, 40-49years) [18]. Wealth index is a measure of relative household economic status and was calculated by DHS from information on household asset ownership using Principal Component Analysis and further categorized into poorest, poorer, middle, richer and richest quintiles [6]. Place of Residence was categorized into urban and rural.

Region was categorized into four; Northern (Teso, Karamoja, Lango, Acholi, West Nile), Central (Kampala, Central 1 and Central 2), Eastern (Busoga, Bugishu and Bukedi) and Western (Tooro, Ankole, Bunyoro and Kigezi) [19]. Level of Education was categorized into: no education, primary education, secondary and higher education. Household Size was categorized as less than six members and six and above members. Sex of Household Head was categorized as male or female. Working status was categorized as: not working and working. Marital Status was categorized into married (this included those in formal and informal unions) and not married. ANC attendance was categorized as yes for any woman who attended ANC regardless of the frequency and no for those who did not attend ANC at all.

\section{Statistical analysis}


We used complex sample analysis to account for the multi-stage cluster study design using SPSS version 25.0 statistical software. Analysis was carried out based on the weighted count to account for the unequal probability sampling in different strata [18] and to ensure representativeness of the survey results at the national and regional level. Each exposure (independent variable) was assessed separately for its association with the outcome variable using bivariable logistic regression and we presented the crude odds ratio (COR), 95\% confidence interval $(\mathrm{Cl})$ and p-values. Independent variables associated with health facility childbirths from literature and those with a p-value $\leq 0.20$ at the bivariable level [20], and not strongly collinear with other independent variables were included in the final multivariable logistic regression model to assess the independent effect of each variable on the outcome variable. All variables in the model were assessed for collinearity, which was considered present if the variables had a variance inflation factor (VIF) greater than 10. Adjusted odds ratios (AOR), 95\% confidence intervals (CI) and pvalues were calculated with statistical significance level set at $p$-value $<0.05$.

\section{Results}

A total of 10,152 women were included in this study (Table 1). Of these, 7,780 (76.6\%) (95\% Cl: 75.8-77.5) had their most recent deliveries at a health facility (public or private-sector health facility) and 2372 $(23.4 \%)$ at home. Majority of the women were residing in rural areas $(76.9 \%)$, in male headed households $(73.1 \%)$, married $(81.3 \%)$, working (83\%), less than 30 years $(59.5 \%)$ had primary as highest level of education $(60 \%)$ and had attended ANC (98.1\%). The mean age and household size were $28.5 \pm 7.14$ and $6.0 \pm 2.80$ respectively.

Table 1: Sociodemographic characteristics of women in Ugandan as per the 2016 UDHS. 


\begin{tabular}{|lll|}
\hline Characteristics & N=10,152 & $\%$ \\
\hline Age & & \\
\hline 15 to 19 & & \\
\hline 20 to 29 & 823 & 08.1 \\
\hline 30 to 39 & 5217 & 51.4 \\
\hline 40 to 49 & 3214 & 31.7 \\
\hline Residence & 899 & 08.9 \\
\hline Urban & & \\
\hline Rural & & \\
\hline Region & 2346 & 23.1 \\
\hline Western & 7806 & 76.9 \\
\hline Eastern & & \\
\hline Central & 2559 & 25.2 \\
\hline Northern & 2113 & 20.8 \\
\hline Sex household head & & 27.7 \\
\hline Female & 2805 & \\
\hline Male & & \\
\hline Household Size & & \\
\hline 6 and Above & & \\
\hline Less than 6 & & \\
\hline Working status & & \\
\hline Not working & & \\
\hline Working & & \\
\hline Marital status & & \\
\hline Married & & \\
\hline Not married & & \\
\hline Education Level & & \\
\hline
\end{tabular}




\begin{tabular}{|lll|}
\hline No Education & 1061 & 10.5 \\
\hline Secondary Education & 2285 & 22.5 \\
\hline Higher & 715 & 07.0 \\
\hline Wealth Index & & \\
\hline Poorest & 2117 & 20.9 \\
\hline Poorer & 2074 & 20.4 \\
\hline Middle & 1921 & 18.9 \\
\hline Richer & 1862 & 18.3 \\
\hline Richest & 2178 & 21.5 \\
\hline Place of Delivery & & \\
\hline Health Facility & 7780 & 76.6 \\
& & \\
\hline Home & & \\
\hline ANC Attendance & & 23.4 \\
\hline Yes & 9957 & 98.1 \\
\hline No & 195 & 01.9 \\
\hline
\end{tabular}

$a_{=}^{a}$ working status missing 7 respondents

Factors associated with health facility delivery.

In the final logistic regression model, factors associated with health facility delivery were: region, age, wealth index, residence, ANC attendance and level of education as indicated in Table 2. Women in younger age groups and those with higher levels of education were more likely to utilize a health facility during childbirth. Higher education attainment, secondary and primary levels of education were $415 \%$, $127 \%$ and $7 \%$ respectively more likely to deliver from a health facility compared to those with no education attainment. ANC attendance, a factor depicting perceived need remained significant in multivariable analysis; those who attended ANC, were $260 \%$ more likely to utilize a health facility during childbirth compared to those who had not attended ANC. Women from wealthier households were more likely to utilize a health facility during childbirth. The effect of location of residence remained significant in the multivariable model with women living in the Northern region were $142 \%$ more likely to utilize a 
health facility during childbirth compared to women from the Central region. Similarly, Women in urban areas were $48 \%$ more likely to utilize a health facility during childbirth compared to those in rural areas.

Table 2: Determinants of health facility utilization at birth among Women in Uganda 


\begin{tabular}{|c|c|c|c|c|}
\hline \multirow[t]{2}{*}{ Characteristics } & $\begin{array}{l}\text { Crude model } \\
(n=10152)\end{array}$ & $\begin{array}{l}\mathrm{p}- \\
\text { value }\end{array}$ & $\begin{array}{l}\text { Adjusted odds ratio } \\
(n=10152)\end{array}$ & $\begin{array}{l}\mathrm{p}- \\
\text { value }\end{array}$ \\
\hline & \multicolumn{2}{|l|}{ COR $(95 \% \mathrm{Cl})$} & \multicolumn{2}{|l|}{ AOR $(95 \% \mathrm{Cl})$} \\
\hline \multicolumn{5}{|l|}{ Age } \\
\hline 40 to 49 & 1 & $<0.001$ & 1 & $<0.001$ \\
\hline 30 to 39 & $1.48(1.24-1.78)$ & & $1.31(1.09-1.59)$ & \\
\hline 20 to 29 & $2.03(1.71-2.41)$ & & $1.57(1.30-1.91)$ & \\
\hline 15 to 19 & $2.32(1.80-3.00)$ & & $2.25(1.71-2.96)$ & \\
\hline \multicolumn{5}{|l|}{ Education Level } \\
\hline No Education & 1 & $<0.001$ & 1 & $<0.001$ \\
\hline Primary & $1.28(1.08-1.52)$ & & 1.07 (0.89 1.27) & \\
\hline Secondary & $4.14(3.27-5.25)$ & & $2.27(1.76-2.92)$ & \\
\hline No Education & $14.70(8.21-26.32)$ & & $5.15(2.79-9.52)$ & \\
\hline Marital Status & & 0.130 & & 0.868 \\
\hline Not married & 1 & & 1 & \\
\hline Married & $0.91(0.80-1.04)$ & & $1.01(0.86-1.20)$ & \\
\hline Working Status & & $<0.001$ & & 0.135 \\
\hline Working & 1 & & 1 & \\
\hline Not working & $1.30(1.06-1.59)$ & & $1.16(0.96-1.41)$ & \\
\hline \multicolumn{5}{|l|}{ Region } \\
\hline Central & 1 & $<0.001$ & 1 & $<0.001$ \\
\hline Western & $0.53(0.40-0.71)$ & & $1.04(0.81-1.34)$ & \\
\hline Eastern & $0.55(0.42-0.72)$ & & $1.15(0.89-1.48)$ & \\
\hline Northern & $0.81(0.62-1.06)$ & & $2.42(1.81-3.22)$ & \\
\hline Household Size & & $<0.001$ & & \\
\hline Less than 6 & 1 & & 1 & 0.263 \\
\hline Six and above & $0.74(0.65-0.83)$ & & $0.93(0.81-1.06)$ & \\
\hline \multicolumn{5}{|l|}{ Wealth Index } \\
\hline Poorest & 1 & $<0.001$ & 1 & \\
\hline Poorer & $0.98(0.82-1.16)$ & & $1.23(1.02-1.48)$ & $<0.001$ \\
\hline
\end{tabular}




\begin{tabular}{|c|c|c|c|c|}
\hline Middle & $1.32(1.07-1.61)$ & & $1.82(1.46-2.27)$ & \\
\hline Richer & $2.01(1.61-2.51)$ & & $2.40(1.87-3.08)$ & \\
\hline Richest & $6.72(5.09-8.88)$ & & $5.14(3.72-7.10)$ & \\
\hline \multicolumn{5}{|l|}{ Residence } \\
\hline Rural & 1 & $<0.001$ & 1 & 0.001 \\
\hline Urban & $3.17(2.52-3.99)$ & & $1.48(1.18-1.86)$ & \\
\hline $\begin{array}{l}\text { Sex of household } \\
\text { head }\end{array}$ & & 0.082 & & 0.482 \\
\hline Male & 1 & & 1 & \\
\hline Female & $1.10(0.97-1.24)$ & & $1.05(0.91-1.22)$ & \\
\hline ANC & & $<0.001$ & & $<0.001$ \\
\hline No & 1 & & 1 & \\
\hline Yes & $4.47(3.04-6.58)$ & & $3.60(2.47-5.24)$ & \\
\hline
\end{tabular}

bold= Significant at $p$-value $<0.05$, Final model - Adjusted for residence, region, age, household size, ANC utilization, sex of household head, level of education, marital status, education level and wealth index. AOR: Adjusted odds ratio. COR: Crude Odds Ratio

\section{Discussion}

This study examined the factors associated with health facility delivery in Ugandan women. We found that almost $80 \%$ of the women gave birth from a health facility. This proportion is higher than national studies that have used similar DHS survey data in Kenya [5], Indonesia [21], Ghana [17]and in other regional studies done in South Sudan [2], Kenya [22] and Ethiopia [23]. Studies that showed a lower proportion of health facility utilization during childbirth compared to our study were done earlier than our study (2011-2014) except Tongun et al. in South Sudan [2] which could partly explain the lower proportions since health facility utilization during childbirth has been shown to increase with time. Furthermore, the differences in the health facilities' access, health system capacity and economic development among these Countries could also explain the observed differences. The significantly low proportion of health facility utilization during childbirth ( $25 \%$, lowest in the region) shown by Tongun et al. in South Sudan could be attributed to the fact that the study was done when the country was experiencing insecurity due to the civil unrest which negatively affected health facility access and led to destruction of infrastructure [2]. South Sudan received independence from Sudan nine years ago and it is still grappling with a weak health infrastructure and system. 
Wealth index, residence, level of education, ANC attendance, age and region were positively associated with health facility delivery utilization. Women belonging to higher wealth quintiles were more likely to give birth from a health facility compared to those in the poorest wealth quintile. Given that Uganda has free health care services [15], our results suggest that, apart from the cost of health services, other economic factors play a key role in influencing the decision-making regarding the place of delivery. This is consistent with findings from other studies have reported economic factors such as transportation costs, and miscellaneous fees paid for healthcare to influence the women's decision regarding the place of childbirth $[17,24]$. Hence there is a need for gaining a deeper understanding of how financial status influences women's decisions regarding choice of place of childbirth. Women belonging to the lower wealth quintiles are more likely to have difficulties in meeting transport and indirect costs related to childbirth in government facilities which prevents them from utilizing health facilities for childbirth [2] and this is further worsened by the high costs of private health facilities [7]. Wealth index has also been shown to be a predictor of health facility deliveries in previous studies done in Kenya, Ghana and South Sudan $[2,5,7,17,22]$.

Urban women were more likely to give birth from a health facility compared to rural women. Urban areas usually have more and better health facilities than rural areas hence easier accessibility of these facilities by urban women unlike rural women who have to cover longer distances to access maternal services, thus ending up giving birth at home $[17,21,25]$. This proximity of health facilities in urban areas ensures better quality of maternal health services through quick referrals and easier use of multidisciplinary teams [17]. In addition, women in urban areas are usually more financially stable, and have more access to media promoting good maternal health $[17,25]$. Place of residence has been shown in other studies done in Indonesia, Ethiopia, Nigeria, Kenya and Ghana $[5,13,17,21,25,26]$ to influence choice of place of childbirth. With this evidence regarding the association between residence and place of childbirth, the government efforts should prioritize improving rural health services in Uganda

Women with secondary and post-secondary education were more likely to give birth from a health facility compared to women with no education. Women with higher levels of education have been shown to have better maternal health literacy, be more receptive to new health related information, increased awareness of available health resources, better decision-making abilities and more financial resources and access to health insurance, which factors have been shown to increase institutional deliveries [2, 22, 27, 28]. With improved maternal health literacy, women become more informed about maternal health care issues which enables them to make positive health care decisions [17]. Maternal education as a predictor of health facility utilization during childbirth has also been evidenced within several other studies $[2,7,17$, $22,23,29]$. Therefore. the government of Uganda needs to intensify girl child education to atleast secondary level and also improve or start maternal health programs targeting the less educated women.

Women who had attended antenatal care were more likely to utilize health facilities for childbirth compared to those who had not attended antenatal care. Visiting of health facilities for antenatal care ensures that the women get health education sessions regarding the benefits of institutional delivery and creates rapport between the health workers and the pregnant women $[7,22,30]$. The health education and 
counselling sessions during antenatal care visits also ensures that women make birth preparedness and complication readiness plans which contributes to increased health facility utilization during childbirth [29]. Antenatal care attendance has also been shown to be a predictor of health facility utilization during childbirth in studies done in similar contexts $[7,8,22,23,29]$.

Younger women were more likely to utilize health facilities during childbirth compared to their older counterparts. Older women tend to have more traditional cohorts hence can easily resist modern health care services [28, 31], and some tend to have a sense of having gained enough experience when it comes to childbirth, hence have less fear for negative pregnancy outcomes associated with home delivery [32, 33]. Age as a predictor of health facility utilization during childbirth has also been evidenced within several other studies $[5,28,33-35]$.

Women from the Northern region were more likely to utilize health facilities during childbirth compared to those in the Central region. This is a surprising finding because the central region is more advanced with a high concentration of health facilities and health care workers. However, our finding is similar to that of Rutaremwa et al. who analyzed the utilization of maternal health services with the 2011 UDHS data [13]. Rutaremwa et al. using Kampala as the reference showed that even if the other four regions were less likely to utilize maternal health services compared to Kampala, Northern region had the highest likelihood of utilizing the desirable maternal health services package compared to the Central, Western and Eastern regions [13]. The differences in health facilities' accessibility, sociocultural context and economic development contribute to the observed regional differences in utilization of health facility at birth [13]. Following the civil war, the Northern region has had many interventions and humanitarian aid mainly targeting maternal health services improvement [36]. The other possible explanation could be that many people were residing in internally displaced peoples' camps and these usually have health facilities provided freely near the camps [36]. However, further research is needed to explore the increased utilization of health facilities at birth in Northern Uganda. Region as a predictor of health facility delivery has been shown in studies done in similar contexts $[5,13,33]$.

\section{Strengths}

Standardized procedures are a requirement of DHS surveys in data collection and validated questionnaires are used which ensures the internal and external validity of the results.

Secondly, we used the most recent nationally representative sample and weighed the data for analysis and therefore our results are generalized to all Ugandan women aged 15 to 49 years.

\section{Limitations}

The cross-sectional design is limited by lack of temporality hence causality inferences cannot be made. Most data on the predictors was based on self-reporting and could not be verified through records which risks socially acceptable answers hence information bias. There is possibility of recall and interviewer 
biases as respondents gave answers about events that occurred in the past and possibility of respondents giving positive answers to please the interviewer. Data on explanatory variables such as wealth, residence reflected the women's conditions at the time of the survey and not at the time of childbirth and hence women may have moved from one category of classification into another. Such nondifferential misclassification may have reduced the strengths of observed associations.

\section{Conclusion}

Our study revealed that health facility utilization during childbirth is higher relative to countries in the East African region and that there are a variety of predictors of Ugandan women's decision about health facility delivery and these included; age, level of education, wealth index, residence, region and ANC utilisation. The identified predictors influence not only the supply but also the demand for health care services, and this highlights the significance of the social determinants of health as well as the need for programs/ interventions that focus beyond improving physical access.

Given that Uganda has free health care services, the study showed that poorer women are less likely to utilize health facility delivery, implying that, apart from the cost of health services, other economic factors influence of place of childbirth and requires thorough exploration in further research. Taken together, it is recommended that maternal health programs should be promoted to target the poor, less educated and older women especially those residing in rural areas in order to increase health facility deliveries in Uganda.

\section{Abbreviations}

EA Enumeration area

AOR Adjusted Odds Ratio

Cl Confidence Interval

COR Crude Odds Ratio

DHS Demographic Health Survey

UDHS Uganda Demographic Health Survey

OR Odds Ratio

SD Standard Deviation

WHO World Health Organization

SPSS Statistical Package for Social Science 
USAID United States Agency for International Development.

\section{Declarations}

\section{Ethics approval and consent to participate}

High international ethical standards are ensured for MEASURE DHS surveys as ethical approval from the country is obtained from a national ethical review board and local authorities before implementing the survey and well-informed verbal consent is sought from the respondents prior to data collection. This data set was obtained from the MEASURE DHS website (URL:

https://www.dhsprogram.com/data/available-datasets.cfm) after getting their permission and no formal ethical clearance was obtained since we conducted secondary analysis of publicly available data.

\section{Consent for publication}

Not applicable.

\section{Availability of data and materials}

Access to the DHS data sets is openly available upon requests made to MEASURE DHS on their website (URL: https://www.dhsprogram.com/data/available-datasets.cfm).

\section{Competing interests}

All authors declare that they have no competing interests.

\section{Funding}

No funding was obtained for this study.

\section{Authors' contributions}

QS conceived the idea, drafted the manuscript, performed analysis and interpreted the results. DM, MM. JK, FEK contributed to results interpretation, reviewed the first draft and drafted the subsequent versions of the manuscript. All authors read and approved the final manuscript.

\section{Acknowledgements}

We thank the MEASURE DHS program for availing us with the data.

\section{References}

1. Micah AE, Hotchkiss DR: Community-level factors associated with the use of facility-based delivery assistance in Uganda: a multilevel analysis. BMC pregnancy and childbirth 2020, 20(1):195-195. 
2. Tongun JB, Mukunya D, Tylleskar T, Sebit MB, Tumwine JK, Ndeezi G: Determinants of Health Facility Utilization at Birth in South Sudan. International journal of environmental research and public health 2019, 16(13):2445.

3. Ronsmans C, Graham WJ: Maternal mortality: who, when, where, and why. Lancet (London, England) 2006, 368(9542):1189-1200.

4. Mukunya D, Tumwine JK, Ndeezi G, Tumuhamye J, Tongun JB, Kizito S, Napyo A, Achora V, Odongkara $B$, Arach $A A$ et al: Inequity in utilization of health care facilities during childbirth: a community-based survey in post-conflict Northern Uganda. Journal of Public Health 2019.

5. Kitui J, Lewis S, Davey G: Factors influencing place of delivery for women in Kenya: an analysis of the Kenya demographic and health survey, 2008/2009. BMC pregnancy and childbirth 2013, 13:40.

6. Uganda Bureau of Statistics - UBOS, ICF: Uganda Demographic and Health Survey 2016. In. Kampala, Uganda: UBOS and ICF; 2018.

7. Eliphas Gitonga et al. Determinants of health facility delivery among women in Tharaka Nithi county, Kenya. Pan African Medical Journal. 2016;25(2):9. [doi: 10.11604/pamj.supp.2016.25.2.10273]

8. Atusiimire LB, Waiswa P, Atuyambe L, Nankabirwa V, Okuga M: Determinants of facility baseddeliveries among urban slum dwellers of Kampala, Uganda. PLoS One 2019, 14(4):e0214995.

9. Vallieres F, Hansen A, McAuliffe E, Cassidy EL, Owora P, Kappler S, Gathuru E: Head of household education level as a factor influencing whether delivery takes place in the presence of a skilled birth attendant in Busia, Uganda: a cross-sectional household study. BMC pregnancy and childbirth 2013, 13:48.

10. Tann CJ, Kizza M, Morison L, Mabey D, Muwanga M, Grosskurth H, Elliott AM: Use of antenatal services and delivery care in Entebbe, Uganda: a community survey. BMC pregnancy and childbirth 2007, 7:23.

11. Amooti-Kaguna B, Nuwaha F: Factors influencing choice of delivery sites in Rakai district of Uganda. Social science \& medicine (1982) 2000, 50(2):203-213.

12. Mbonye AK, Asimwe JB: Factors associated with skilled attendance at delivery in Uganda: results from a national health facility survey. International journal of adolescent medicine and health 2010, 22(2):249-255.

13. Rutaremwa G, Wandera SO, Jhamba T, Akiror E, Kiconco A: Determinants of maternal health services utilization in Uganda. BMC Health Serv Res 2015, 15:271.

14. Benova L, Dennis ML, Lange IL, Campbell OMR, Waiswa P, Haemmerli M, Fernandez Y, Kerber K, Lawn JE, Santos AC et al: Two decades of antenatal and delivery care in Uganda: a cross-sectional study using Demographic and Health Surveys. BMC health services research 2018, 18(1):758-758.

15. Chi PC, Bulage $P$, Urdal $H$, Sundby J: A qualitative study exploring the determinants of maternal health service uptake in post-conflict Burundi and Northern Uganda. BMC pregnancy and childbirth 2015, 15:18.

16. Montagu D, Yamey G, Visconti A, Harding A, Yoong J: Where do poor women in developing countries give birth? A multi-country analysis of demographic and health survey data. PLOS One 2011, 
6(2):e17155.

17. Dankwah E, Zeng W, Feng C, Kirychuk S, Farag M: The social determinants of health facility delivery in Ghana. Reproductive Health 2019, 16(1):101.

18. Abrha S, Shiferaw S, Ahmed KY: Overweight and obesity and its socio-demographic correlates among urban Ethiopian women: evidence from the 2011 EDHS. BMC Public Health 2016, 16:636.

19. Yang YY, Kaddu G, Ngendahimana D, Barkoukis H, Freedman D, Lubaale YA, Mupere E, Bakaki PM: Trends and determinants of stunting among under-5s: evidence from the 1995, 2001, 2006 and 2011 Uganda Demographic and Health Surveys. Public health nutrition 2018, 21(16):2915-2928.

20. Lee PH, Burstyn I: Identification of confounder in epidemiologic data contaminated by measurement error in covariates. BMC medical research methodology 2016, 16:54-54.

21. Efendi F, Ni'mah AR, Hadisuyatmana S, Kuswanto H, Lindayani L, Berliana SM: Determinants of Facility-Based Childbirth in Indonesia. The Scientific World Journal 2019, 2019:9694602.

22. Kawakatsu Y, Sugishita T, Oruenjo K, Wakhule S, Kibosia K, Were E, Honda S: Determinants of health facility utilization for childbirth in rural western Kenya: cross-sectional study. BMC pregnancy and childbirth 2014, 14:265.

23. Hailu D, Berhe $\mathrm{H}$ : Determinants of institutional childbirth service utilisation among women of childbearing age in urban and rural areas of Tsegedie district, Ethiopia. Midwifery 2014, 30(11):11091117.

24. Borghi J, Ensor T, Neupane BD, Tiwari S: Financial implications of skilled attendance at delivery in Nepal. Tropical Medicine \& International Health 2006, 11(2):228-237.

25. Alemayehu M, Mekonnen W: The Prevalence of Skilled Birth Attendant Utilization and Its Correlates in North West Ethiopia. BioMed Research International 2015, 2015:436938.

26. Onah HE, Ikeako LC, Iloabachie GC: Factors associated with the use of maternity services in Enugu, southeastern Nigeria. Social science \& medicine (1982) 2006, 63(7):1870-1878.

27. Ngowi AF, Kamazima SR, Kibusi S, Gesase A, Bali T: Women's determinant factors for preferred place of delivery in Dodoma region Tanzania: a cross sectional study. Reproductive Health 2017, 14(1):112.

28. Gabrysch S, Campbell OMR: Still too far to walk: Literature review of the determinants of delivery service use. BMC pregnancy and childbirth 2009, 9(1):34.

29. Hamdela B, Getnet Y, Abageda M (2015) Predictors of Health Facility Delivery Service Utilization in Lemo District, South Ethiopia: Unmatched Case Control Study. J Preg Child Health 2:152. doi: 10.4172/2376-127X.1000152.

30. Sserwanja, Q., \& Kawuki, J. (2020). Prevalence of Underweight and Associated Factors among Lactating Women in Ethiopia: A Mini-review. Journal of Advances in Medicine and Medical Research, 32(8), 1-9. https://doi.org/10.9734/jammr/2020/v32i830459.

31. Tebekaw Y, James Mashalla Y, Thupayagale-Tshweneagae G: Factors Influencing Women's Preferences for Places to Give Birth in Addis Ababa, Ethiopia. Obstetrics and Gynecology 
Internationa/ 2015, 2015:439748.

32. Envuladu E, Agbo H, Lassa S, Kigbu J, Zoakah A. Factors determining the choice of a place of delivery among pregnant women in Russia village of Jos north, Nigeria: achieving the MDGs 4 and 5. Int J Med Biomed Res. 2013;2(1):23-7.

33. Bbaale E, Guloba A: Maternal education and childbirth care in Uganda. The Australasian medical journal 2011, 4(7):389-399.

34. Bhattacharyya S, Srivastava A, Roy R, Avan BI: Factors influencing women's preference for health facility deliveries in Jharkhand state, India: a cross sectional analysis. BMC pregnancy and childbirth 2016, 16:50.

35. Say L, Raine R: A systematic review of inequalities in the use of maternal health care in developing countries: examining the scale of the problem and the importance of context. Bulletin of the World Health Organization 2007, 85(10):812-819.

36. Namasivayam A, Arcos González P, Castro Delgado R, Chi PC: The Effect of Armed Conflict on the Utilization of Maternal Health Services in Uganda: A Population-based Study. PLoS currents 2017, 9. 